\title{
Operation of W7-X with an inertially cooled divertor - on the way to steady state operation
}

\author{
H.-S. Bosch, S. Äkäslompolo, R. Brakel, V. Bykov, P. Drewelow, J. Geiger, M. Jakubowski, M. \\ Nagel, D. Naujoks, K. Risse, T. Rummel, P. van Eeten, W7-X-Team
}

\begin{abstract}
The superconducting stellarator Wendelstein 7-X has completed the first three experiment phases, the first one with a limiter only and two phases with an inertially cooled carbon divertor configuration. The main mission of the latter two phases (the last one with two scraper elements) was to pave the way for the planned steady state-operation with high power plasmas and a steady-state divertor. Presently, the device is being completed by installing a High-Heat-Flux (HHF) divertor, the corresponding water-cooling and ten cryo pumps in the divertor chambers. After this completion phase of $\mathrm{W} 7-\mathrm{X}$ the device is ready for long pulse divertor operation with heating power beyond $10 \mathrm{MW}$.
\end{abstract}

Index Terms - Stellarator, Operation, Divertor operation, Steady-state operation.

\section{INTRODUCTION}

The optimized, superconducting stellarator Wendelstein 7-X (W7-X) [1, 2] has started operation in December 2015. Meanwhile three experimental phases with different carbon invessel configurations (limiter, inertially cooled divertor without and with "scraper elements") have been performed, and important physics results have been achieved already [3]. These three operation phases were directed to develop the scenarios for steady state divertor plasmas in W7-X. In this paper a technical summary of the last operation phases and of the technical processes to get to these plasmas are be discussed. Presently, up to the end of 2020, a steady-state (completely water-cooled) carbon fiber composite (CFC) divertor, watercooled baffles and 10 cryo pumps (one behind each divertor module) are being assembled in and around the $\mathrm{W} 7-\mathrm{X}$ device [4]. After this completion, the mission of W7-X can finally start: Thirty minutes discharges with an input power of more than $10 \mathrm{MW}$ should prove the steady state operation on all time scales. An overview of the changes to W7-X periphery will be described. The paper is organized as follows: first, a general overview on the three operational phases is provided before more details on the operation of the device in the last phase (OP 1.2b) is given. We conclude with a short summary

"This work has been carried out within the framework of the EUROfusion Consortium and has received funding from the Euratom research and training programme 2014-2018 and 2019-2020 under grant agreement No 633053. The views and pinions expressed herein do not necessarily reflect those of the European Commission."

All authors are with the Max-Planck-institute for Plasma Physics in Greifswald, Germany (e-mail: author@ ipp.mpg.de). The main author can be contacted under: bosch@ipp.mpg.de about the work on equipping the device with a fully cooled divertor for steady-state operation and a brief outlook on future tasks at the device.

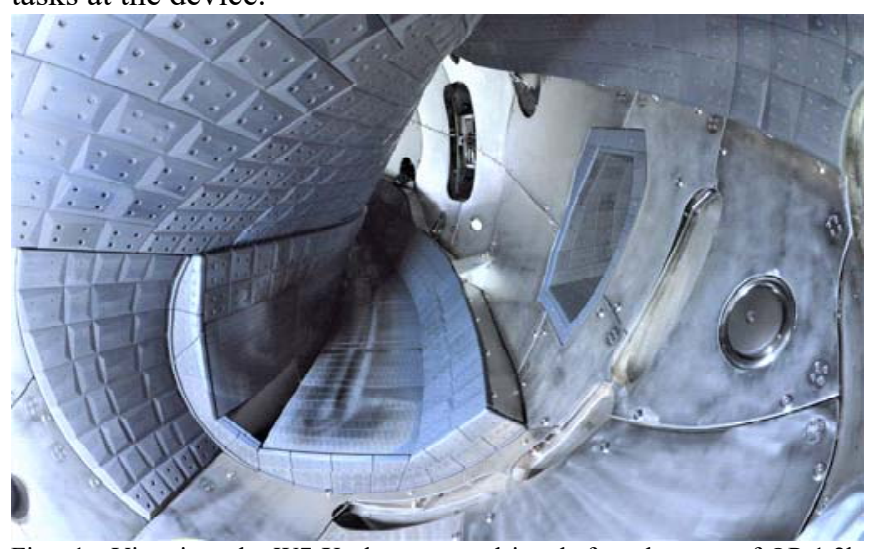

Fig. 1. View into the W7-X plasma vessel just before the start of OP $1.2 \mathrm{~b}$. Shown here is module 2 with a glow discharge electrode on the right wall, an NBI entrance port (shielded by C-tiles) and one of the bottom TDU. This consists (from the right) toroidal divertor closure, outer baffle, horizontal target plate, divertor pump slit, horizontal target plate and inner baffle. On the front, the vertical divertor closure is visible. On both of the target plate, the traces of the separatrix are well visible. (courtesy G.Wurden/LANL)

\section{OPERATION OF W7-X 2015-2018}

A. Overview of the first three operation phases

The first operation phase started in December 2015 with five C-limiters at the inner wall. After cleaning with ECRH-pulses and, from January 2016 on, also with Glow Discharge Cleaning, the plasma performance - in $\mathrm{He}$ and later in $\mathrm{H}_{2}$ - was very good [5].

For the second operation phase - in 2017/8 - a temporary Test Divertor Unit (TDU) was installed in W7-X, see Fig. 1. This inertially cooled divertor from carbon had the same shape as the finally foreseen High-Heat-Flux divertor (HHF) with ten divertor units (one on top and one on the bottom of the plasma vessel, in each of the 5 modules). However, the target plates were made from fine-grain graphite and rather thick to have a robust divertor for the first divertor operation [6]. The mission for this phase was the development of divertor scenarios for the later steady-state phases with the HHF divertor [7]. In the middle of this second operation phase, a break was put in to install two so-called scraper elements[ 8] to protect the divertor during the build-up of a toroidal bootstrap current[9], if significant current may be present. This additional installation divided the second operation phase into OP 1.2a and OP 1.2b. 
Summaries of the physics results of these operation phases have been published elsewhere [3, 10]. Reviews and lessons learned on technical operation of W7-X from OP 1.1 and OP 1.2a have been collected in $[2,11]$.

Experiments in all phases have been run at 2 or 3 days per week, alternating. The superconducting magnetic field has been run stationary during an experiment day (with agreed transitions from one configuration to another), but shut down in the evening. After the commissioning of the device W7-X, about 23 weeks have been used to commission W7-X with magnetic field to calibrate diagnostics, to introduce and to check new field configurations, to measure magnetic flux surfaces, cleaning the plasma vessel surfaces and so on. Table 1 summarizes the performance data for the three operation phases.

\begin{tabular}{|l|c|c|c|}
\hline & OP 1.1 & OP 1.2a & OP 1.2b \\
\hline plasma discharges & 776 & 1156 & 1120 \\
\hline test pulses & 148 & 257 & 277 \\
\hline fault pulses & 24 & 98 & 211 \\
\hline Total & $\mathbf{9 4 8}$ & $\mathbf{1 5 1 1}$ & $\mathbf{1 6 0 8}$ \\
\hline
\end{tabular}

\begin{tabular}{|l|c|c|c|}
\hline start of the campaign & 09.12 .2015 & 01.08 .2017 & 17.06 .2018 \\
\hline end of the campaign & 10.03 .2016 & 08.12 .2017 & 18.10 .2018 \\
\hline weeks of operation & 13 & 18 & 18 \\
\hline experiment days & 33 & 40 & 44 \\
\hline thereof commissioning & 4 & 5 & 8 \\
\hline
\end{tabular}

Table 1. Summary of the first three operation phases of W7-X. OP 1.1 was performed in a limiter configuration, OP 1.2 with an inertially cooled test divetor, in OP $1.2 \mathrm{a}$ without the two scraper elements, OP $1.2 \mathrm{~b}$ with them.

The large number of fault pulses in OP $1.2 \mathrm{~b}$ is attributed to electrical discharges in the ECRH towers due to the increased humidity in the summer of 2018. Meanwhile, the air in the ECRH tower is being cooled and dried, to avoid arc ignition by electronic radiation [12].

\section{B. Operation of $W 7-X$ in $O P 1.2 b$}

In the last experiment phase, OP $1.2 \mathrm{~b}$, new main components on W7-X were taken into operation, mainly the boronization system and the neutral beam injection with one beam box (2 sources, $55 \mathrm{kV} \mathrm{H}$-neutrals) [13]. Both of these components are discussed below.

\section{1) Boronization of the plasma vessel}

An optimised wall conditioning strategy has been developed and consistently applied throughout the recent campaign of W7$\mathrm{X}$ operation [14]. Seven days of baking at $150^{\circ} \mathrm{C}$ flat top, were followed by 9 hours of glow discharge cleaning (GDC) in hydrogen. Thus, the major outgassing impurities $\mathrm{H}_{2} \mathrm{O}, \mathrm{CO}_{2}$, $\mathrm{CO} / \mathrm{N}_{2}$ and $\mathrm{CH}_{4}$ were removed. A final GDC in helium removed most of the $\mathrm{H}_{2}$ from the surfaces and provided the start-up conditions for W7-X operation. Residual $\mathrm{H}_{2}$-outgassing during initial plasma operation could be successfully reduced by ECRH-pulse trains in He. At the end of daily operation, the $\mathrm{H}_{2}-$ loaded walls were depleted by He-GDC. At this stage of conditioning the plasma density achievable with gas fuelling only and ECRH heating was limited to $5 \times 10^{19} \mathrm{~m}^{-3}$ due to impurity radiation losses.

On August 4, 2018, during OP 1.2b, the first boronization at W7-X took place [15]. This opened access to a new density regime up to $1 \times 10^{20} \mathrm{~m}^{-3}$, see Fig. 2 . The reason for that is the strong reduction of $\mathrm{C}$ and $\mathrm{O}$ impurity radiation, which is attributed to gettering of oxygen by the boron layer and the associated reduction of chemical sputtering of carbon via $\mathrm{CO}$. Furthermore, significant neutral gas compression in the divertor was achieved only after boronization, allowing for effective pumping. The regular daily He-GDC could be suspended. These new conditions were long term stable. However, two further boronizations followed in 4-week intervals, but they did not result in an additional improvement.

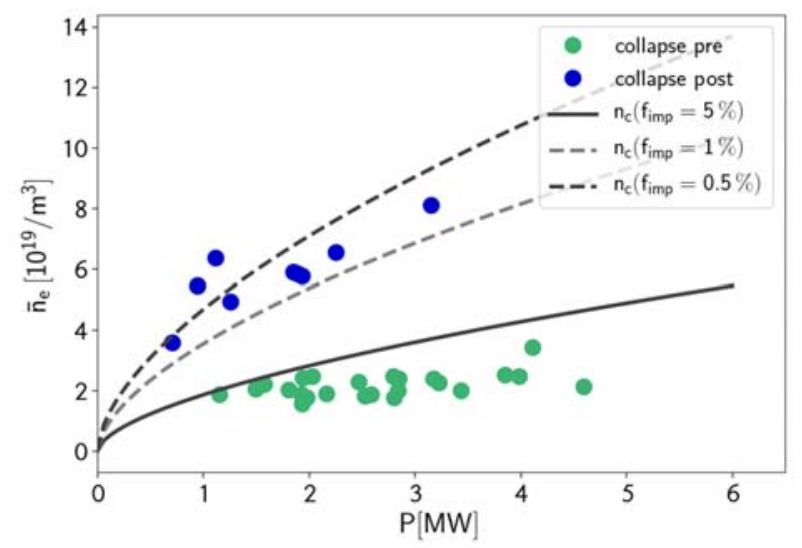

Fig. 2. Line averaged densities as a function of the input power, before (green points) and after boronization (blue points). The difference of the point distribution can be explained by the impurity content, as shown by the lines for different carbon fractions.

\section{2) Magnetic field scenarios}

W7-X has 70 superconducting coils of seven types. For operating W7-X, all ten coils of one type are supplied in series by an independent power supply [16, 17]. These seven, independent coil currents offer in general a wide range of magnetic configurations (characterized by iota, shear, magnetic well/hill, inward-/outward-shift, toroidal mirror fields) [18]. A base set of magnetic configurations had been developed for the specification of the coils, the power supplies, and the support structures. Most of these magnetic configurations have been commissioned already, and used in plasma discharges. Fig. 3 shows the distribution of magnetic field configurations used in OP $1.2 \mathrm{~b}$. Newly commissioned was the low iota configuration and the configurations required for a scan from low- to highiota.

Since laying out these base configurations, new developments in plasma physics and a better understanding of fast ion behaviour in $\mathrm{W} 7-\mathrm{X}$, produced by neutral beam injection (NBI) resulted in requirements for new configurations, beyond the original specification.

Since the electric network with the coil protection system is a coupled network, not all current distributions are possible [19]. Also the mechanical loads between the coils (transferred with the non-linear inner and outer support elements and by the 
central support bolts fixing planar coils to the central support ring) as well as the mechanical coupling of planar coils to nonplanar coils sets stringent limits to the coil current distribution in the seven electrical circuits [20].

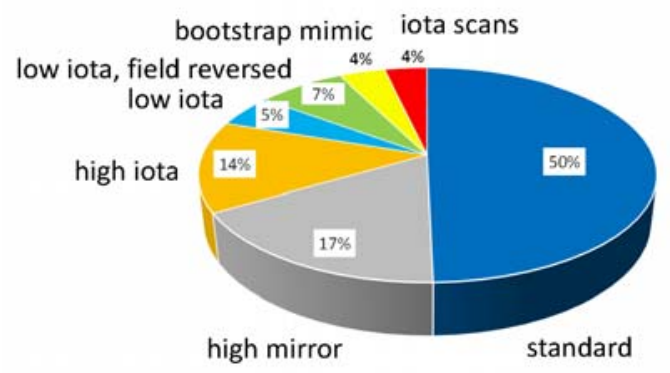

Fig. 3. Distribution of the magnetic field configuration in OP $1.2 b$. Newly commissioned was the low iota configuration, also performed with a reversal in all the superconducting coils. Also new were the iota-scans covering the transition from high to low iota configurations.

Therefore, newly proposed magnetic configurations have to be approved by the magnet group (after calculating the current inside the network in case of a fast discharge) [21] by the mechanical engineering group (checking for the mechanical loads on the support structure described above) [22]. New configurations, possible to perform correctly, have to be released formally by the Head of Operation.

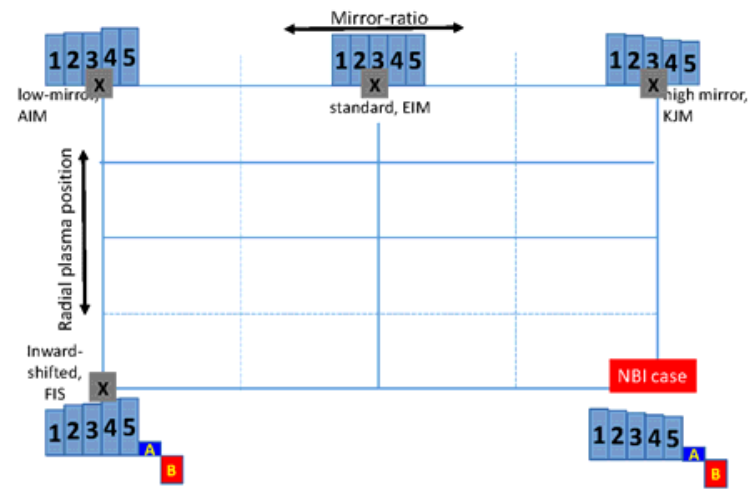

Fig. 4. Schematic cut in the magnetic configuration phase space, spanned by the coil currents in the seven different coil types. Four of the standard configurations are shown in grey. Along the x-axis, the mirror ratio is varied, the $y$-axis shows the radial position of the plasma. In the standard configuration, the currents in all five non-planar coils are equal, increasing currents from coil 1 to coil 5 lowers the mirror ratio. In these cases, shown on the top of the figure, no current in planar coil is used. Invoking also the planar coils, with different direction of the 2 types of planar coils, as shown below the $\mathrm{x}$-axis, shifts the plasma inwards. The magnetic configuration proposed for NBI, extends to a previously not covered phase space range.

One example for this process was the introduction of neutral beam heating in W7-X. An operation issue was the behaviour of the fast ions and their loss from the plasma. Recent simulations of the heat load by fast particles onto the plasma wall using ASCOT [23] revealed problems [24], resulting in local hot spots on the plasma wall and on some diagnostic tubes [24]. While these immersion tubes could be shielded locally, the problem of possible local overloading at plasma wall components, required the selection of special magnetic field configurations [25]. This selection is presented in Fig. 4, showing a shematic cut in the magnetic configuration phase space, spanned by the coil currents in the seven different coil types. Four of the standard configurations are indicated in grey, with a name and a three-digit (internal) identifier. The configuration, proposed for the start-up of NBI having very low fast ion losses, sits in the right lower corner, i.e. a high-mirror, inward-shifted plasma.

This figure also shows schematically how the configurations differ in the coil currents. To vary the mirror ratio (along the $\mathrm{x}$ axis), the ratio in the non-planar coils is varied, as sketched in Fig. 4. In the standard configuration as well as in low- and highmirror configuration cases, no current in the planar coils is used. Invoking also the planar coils, with different current directions of the 2 types of planar coils, the plasma moves inwards.

As can be seen clearly, the magnetic configuration proposed for NBI, extends to a previously not covered phase space range. Therefore, this region had to be investigated in more detail.

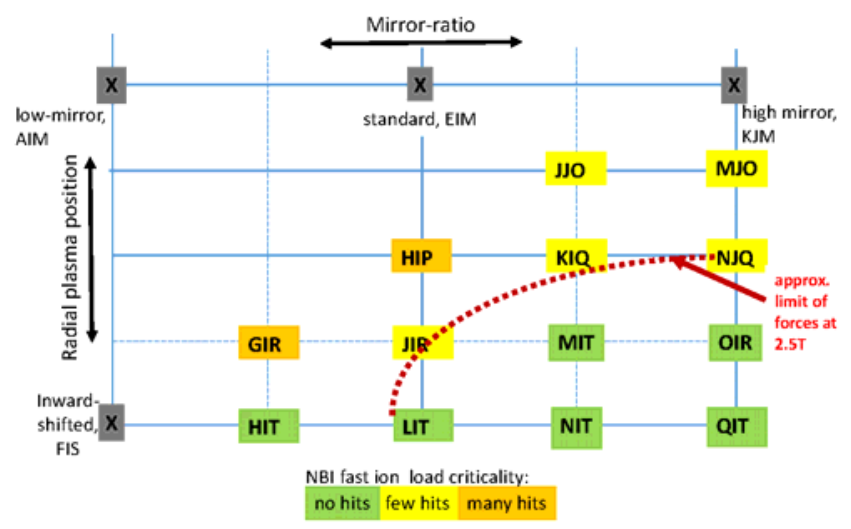

Fig. 5. In the phase space shown in Fig. 4, the behavior of the fast particles was calculated for some theoretical configuration (named with an internal 3-letter code). The color code of these IDs, as shown in the legend, describes qualitatively the loss of fast particle, clearly showing why the lower right corner is preferred for NBI.

However, also the mechanical loads in the coil system has been calculated for these cases, and below the red, broken line, forces and moments are beyond the allowable limit.

1) ASCOT modelling was used to determine the fast losses for a number of configurations as shown Fig. 5, at least qualitatively. Green color around the configuration ID indicated very low ion losses, yellow somewhat higher ones, and orange indicated large loads from fast particles. The first result of this study was, to use a high-mirror-like configuration as indicated on the right side in Fig. 4 and named "QIT".

2) However, as indicated above, also the forces and moments within the non-linear magnetic coil support (coils and supports) have to be taken into account [26]. The modelling of the configurations in Fig. 5 
demonstrated a very clear border, indicated by the red, broken line. Below this limiting line, the forces and moments are beyond the allowable limits.

As a result, the NBI-experiments, plasmas were performed without inward shift in the high-mirror or the standard configuration. The fast ion losses have been visible, but with relatively low loads, not harming the device [27].
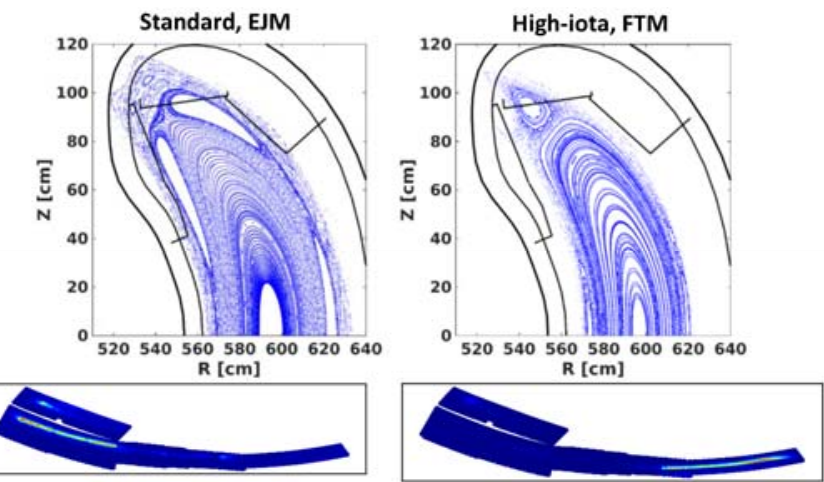

Fig. 6 Poincaré plots of the magnetic surfaces in the upper half of the plasma vessel for different magnetic configurations (standard and high-iota). Below, the load, measured by thermography cameras, on the divertor components (see Figure 7) are shown.

\section{3) Increasing the heating energy into the plasma}

The specification for OP $1.2 \mathrm{a} / \mathrm{b}$ foresaw an integrated input energy into the plasma $\left.\left(\int \mathrm{P}_{\text {heat }} \cdot \mathrm{dt}\right)=\mathrm{W}_{\text {input }}\right)$ of $\mathrm{W} 7-\mathrm{X}$ of $80 \mathrm{MJ}$. In OP 1.2a, this limit was increased to $200 \mathrm{MJ}$, as the load on the in-vessel components turned out to be well distributed, without significant asymmetries. For increasing $\mathrm{W}_{\text {input }}$, again an organisational process got introduced to increase $\mathrm{W}_{\text {input }}$ in predefined steps. This has to be done for each magnetic configuration separately, as the wall loads and their distribution depend very strongly on the shape and position of the plasma, see Figure 6. Asymmetries in the load on the 10 divertor targets

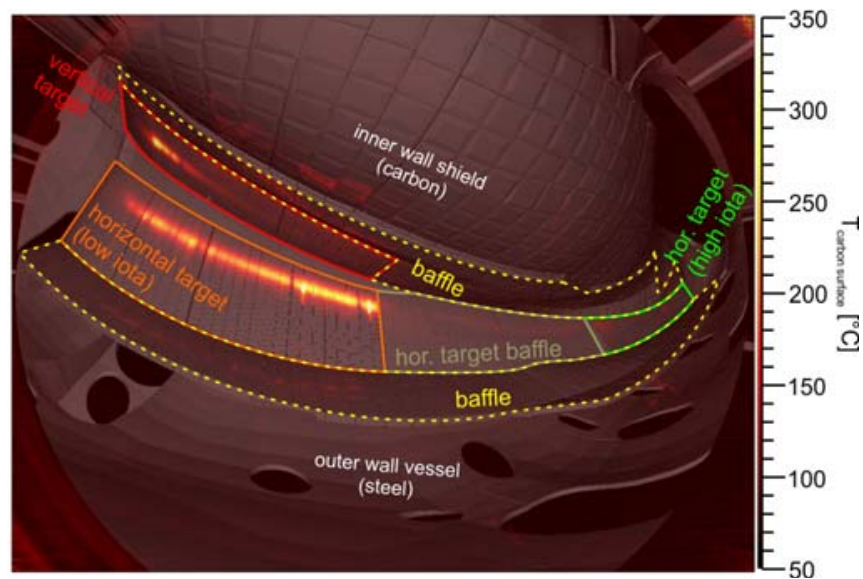

Fig. 7 IR thermography picture from one divertor module in a standard magnetic configuration discharge. For information, a visible picture is overlaid and the different parts of the divertor are indicated. (courtesy of P. Drewelow) had been mitigated, using the trim coils outside the plasma vessel [28, 29], and furthermore divertor loads have been symmetrized with the non-superconducting coils [30].

The limiting criteria to get to a higher level of $\mathrm{W}_{\text {input }}$ were different temperature levels of the divertor components (observed by IR thermography, see Fig.7), temperatures of the TDU tiles frame (thermocouples), temperatures at the NBI beam-dumps and on diagnostics as well as the observation of hot spots in the plasma vessel. A layout of one TDU module, overlaid with an IR picture is shown in Fig. 7. To exemplify this, The process to increase $\mathrm{W}_{\text {input }}$ will be described for two cases:

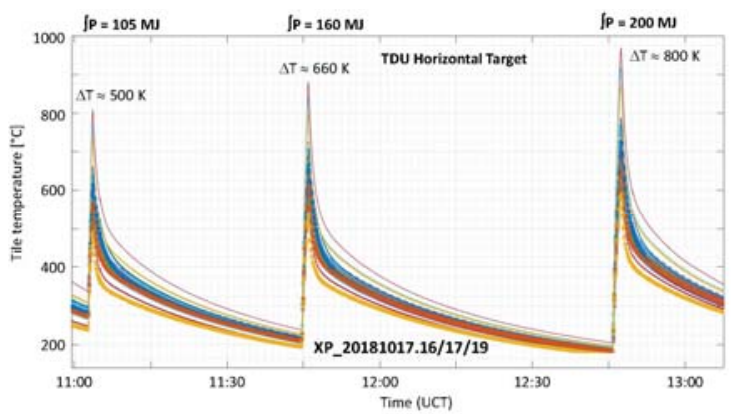

Fig. 8 Divertor target temperatures, measured with thermocouples in the heavily loaded "high iota tail" of the different modules. This sequence covers the three last discharges in the process of increasing $\mathrm{W}_{\text {input }}$ to $200 \mathrm{MJ}$ (see labels on the top).
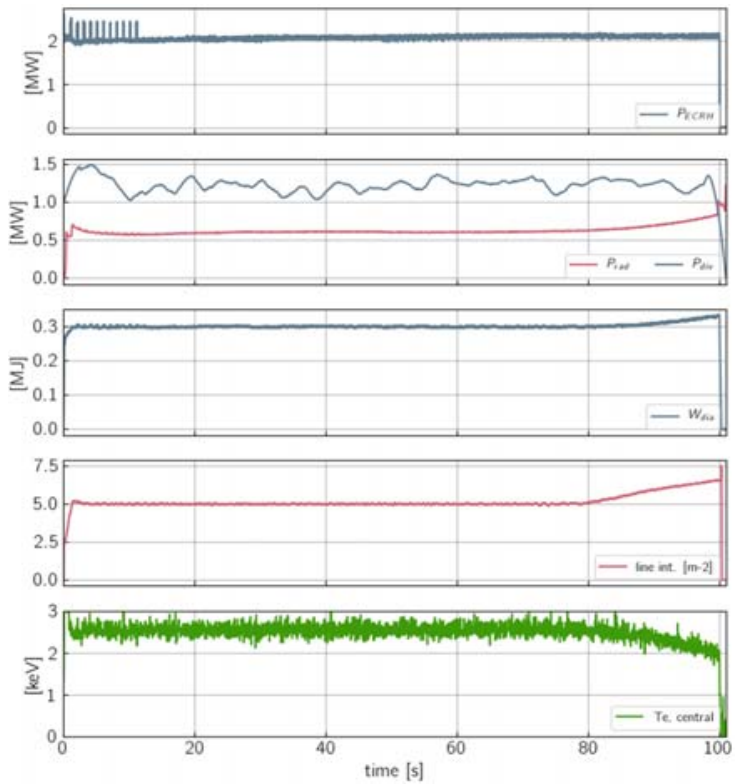

Fig. 9 Time traces of main parameters of the $100 \mathrm{~s}$ long discharge 20181017.019.

For achieving a long, i.e. $100 \mathrm{~s}$, discharge, obviously the heating power has been cautiously restricted to $2 \mathrm{MW}$. For this task, a high-iota magnetic configuration (Figure 6 right side) was chosen, were the thermal load is deposited on the so-called "high iota tail" of the divertor target (Figure 6, bottom right) target. To approve the Winput limit of $200 \mathrm{MJ}$, several steps were required. Figure 8 shows the thermal load on several positions in the 10 divertors, for the last three steps in this ladder, i.e. $\mathrm{W}_{\text {input }}$ at 105,160 , and $200 \mathrm{MJ}$. The rise in the temperature in a single discharge increases from $\approx 500 \mathrm{~K}$ to $\approx$ 
$800 \mathrm{~K}$, but all temperatures are in the allowed region. Figure 9 demonstrates the key parameters of the 100 s (i.e. $200 \mathrm{MJ}$ ) discharge 20181017.019.

Steady state divertor discharges have to use the detached divertor regime [31, 32], where the heat load is radiated in the edge and the divertor plasma regions, with only a rather low thermal load onto the divertor targets. This scenario requires higher density in the flux surfaces outside the plasma core and higher ECRH levels.

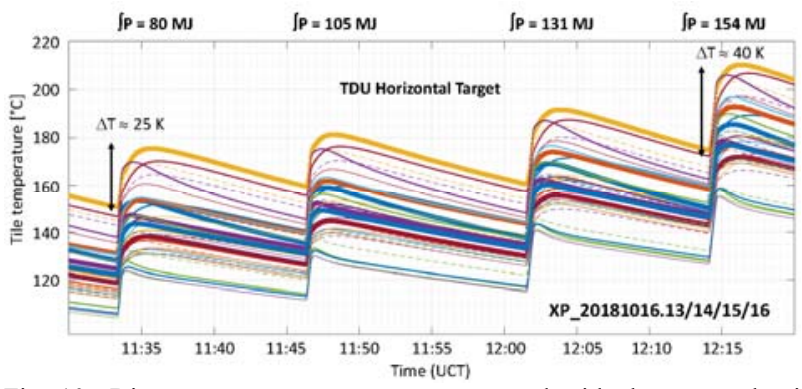

Fig. 10 Divertor target temperatures, measured with thermocouples in the horizontal target plates of different modules. This sequence covers the four last discharges (in the "magnetic standard configuration") in the process of increasing $\mathrm{W}_{\text {input }}$ to $154 \mathrm{MJ}$ (see labels on the top).
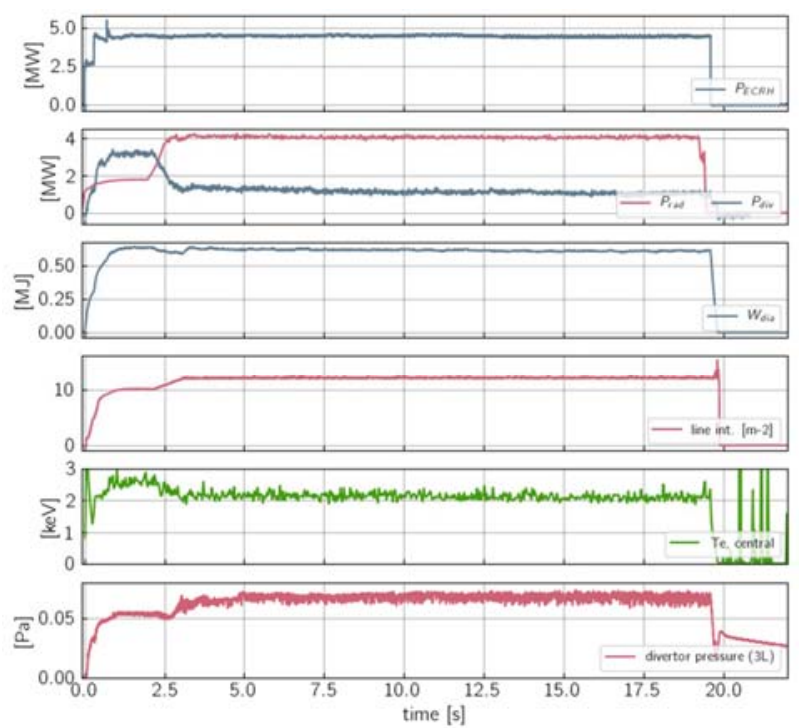

Fig. 11 Time traces of the main parameters for the detached discharge $20181016.014\left(\mathrm{~W}_{\text {input }}=105 \mathrm{MJ}\right)$. After $2.5 \mathrm{~s}$ the divertor load decreases strongly while the radiated power increases. At the same time the divertor neutral gas pressure (bottom curve) increases by about $20 \%$, indicating high divertor recycling.

Such experiments have been performed in different magnetic configurations [33], the longest discharge with a detached divertor plasma was a "standard magnetic configuration" discharge with $154 \mathrm{MJ}$, similar to Figure 6 (left) and 7. The development of the temperature load to the divertor is shown in Figure 10. In contrast to Figure 8, the temperature increase on the target plates is much smaller, although the input power into these plasmas is higher by a factor of 2.3. After the $154 \mathrm{MJ}$ discharge no further increase of the input energy was possible, due to safety switch-offs of gyrotrons by the ECRH arc detection system, as mentioned before. Details of the longest detached discharge, with $30 \mathrm{~s}$ detached conditions are reported in [33]. Figure 11 shows the main parameters for the discharge 20181016.014 (Winput $=105 \mathrm{MJ}$ ). After $2.5 \mathrm{~s}$ the divertor plasma is detached, i.e. the convective and conductive loads onto the divertor targets decreases strongly while the radiated power in the scrape-off layer increases. At the same time, the divertor neutral gas pressure (bottom curve in Fig. 11) increases by about $20 \%$, indicating high divertor recycling.

\section{Completion of W7-X}

Presently, W7-X is being completed to allow the steady-state operation. The main task is the installation of a steady-state divertor [7], water-cooled baffles (both components completely water-cooled) and 10 cryo pumps (one behind each divertor module) [34] are being assembled in the W7-X device [4].

Outside the torus, the peripheral components have to be extended in order to provide the in-vessel components with cooling water, and the cryo pumps with LN2 and LHe [35, 36].

In addition to these large divertor-related components, also the heating devices are being extended and new ones installed [37], the diagnostics are being extended [38], especially for the observation of the HHF-flux divertor. This urgently requires steady-state water-cooling, and therefore also in-situ supervision of the surface temperatures to detect a overload condition [39] and to safely shut down the plasma heating by the central fast interlock system [40].

\section{Outlook for the steady-state of W7-X}

After this completion, the mission of W7-X can finally start: Thirty minutes discharges with an input power of more than 10 MW should prove the capability of steady state operation on all time scales.

Having prepared the device W7-X for this task, more efforts have to be spent on ensuring a steady-state plasma observation with the multitude of diagnostics at W7-X.

\section{E. Summary}

Since the start at the end of 2015, W7-X has completed three operation phases very successfully. Especially in the last of these phases, performed in 2018, the energy input into the plasma has been increased to $200 \mathrm{MJ}$, allowing about $30 \mathrm{~s}$ long, detached divertor discharges with $5 \mathrm{MW}$ ECRH power and 100 $\mathrm{s}$ long discharges with lower heating power.

At the same time, the NBI was taken into operation, while optimizing the magnetic field configuration in order to minimize the fast ion losses and minimizing the mechanical loads in the coil system. 


\section{REFERENCES}

[1] J. Nührenberg et al., "Overview on Wendelstein 7-X theory," Fusion Technol., vol. 27, no. 3T, pp. 71-78, 1995.

[2] H.-S. Bosch et al., "Final integration, commissioning and start of the Wendelstein 7-X stellarator operation," Nucl. Fusion, vol. 57, no. 11, p. 116015,2017

[3] T.S. Pedersen et al., "First results from divertor operation in Wendelstein 7-X," Plasma Physics Contr. Fusion, vol. 61, p.014035, 2019.

[4] L. Wegener et al., "Engineering lessons learned in the commissioning, initial operation and in the further upgrading of Wendelstein 7-X" to be published in IEEE Trans Plasma Sciences 2019.

[5] R. Wolf et al., "Major results from the first plasma campaign of the Wendelstein 7-X stellarator," Nucl. Fusion, vol. 57, no. 11, p. 102020, 2017.

[6] A. Peacock et al., "Progress in the design and development of a test divertor (TDU) for the start of W7-X operation," Fusion Engineering and Design, vol. 84, pp. 1475-1478, 2009

[7] R. Stadler et al., "The in-vessel components of the experiment Wendelstein 7-X," Fusion Engineering and Design, vol. 84, pp. 305-308, 2009.

[8] A. Lumsdaine et al., "Design of the Wendelstein 7-X inertially cooled Test Divertor Unit Scraper Element," Fusion Engineering and Design, vol. 98-99 pp.1357-1361, 2015.

[9] A. Lumbsdaine et al., "Design and analysis of divertor scraper elements for the W7-X stellarator," IEEE Trans. Plasma Sciences, vol. 42, pp. 539-544, 2014.

[10] R. Wolf et al., "Performance of Wendelstein 7-X stellarator plasmas during the first divertor operation phase," Physics of Plasmas, 2019.

[11] H.-S. Bosch et al., "Engineering Challenges in W7-X: lessons learned and status for the second operation phase," IEEE Trans. Plasma Sciences, vol. 46, pp. 1131-1140, 2018.

[12] S. Marsen et al., "The Wendelstein 7-X ECRH plant - Operational experience and planned upgrades," submitted to the Workshop on RF Heating Technology of Fusion Plasmas 2019

[13] D. Hartmann et al, "First time neutral beam heating on Wendelstein7-X," presented at $46^{\text {th }}$ EPS Conf. Plasma Physics, Milano, 2019,

[14] T. Wauters et al., "Wall conditioning by ECRH discharges and He-GDC in the limiter phase of Wendelstein 7-X," Nucl. Fusion, vol. 58, p. 066013 , 2018.

[15] R. Brakel et al., "Strategy and optimisation of wall conditioning at the Wendelstein 7-X Stellarator,” Preprint 2018: IAEA Fusion Energy Conference, Gandhinagar [EX/P8-17. P 404].

[161] Th. Rummel et al., "Power supplies for the Wendelstein 7-X stellarator," Fusion Engineering and Design, vol. 66-68, pp.1115-1118, 2003.

[17] Th. Mönnich et al., "Protection system for the superconducting coils in Wendelstein 7-X," Fusion Engineering and Design, vol. 66-68, pp.1041-1044, 2003.

[18] T. Andreeva, "Vacuum Magnetic Configurations of Wendelstein 7-X," report IPP-III-270, Max-Planck-Institut für Plasmaphysik, May 2002. http://hdl.handle.net/11858/00-001M-0000-0027-450D-A

[19] T. Rummel et al., „Challenges for the Wendelstein 7-X magnet system during the next operation phase," IEEE Trans. Plasma Sciences, vol. 46, pp 1517-1521, 2018

[20] V. Bykov et al.,'Specific Features of Wendelstein 7-X Structural Analyses," IEEE Trans Plasma Sciences, vol. 42, no. 3, pp. 690-697, 2014.
[21] K. Risse et al., „Updates on protection system for Wendelstein 7-X superconducting magnets," Fusion Engineering and Design in press Doi: 10.1016/j.fusengdes.2019.01.111

[22] V. Bykov et al., "Mechanical Monitoring Issues in Preparation to Next Step of Wendelstein 7-X Operation," Trans Plasma Science, vol. 46, pp. 1086-1094, 2018, 2018

[23] E. Hirvijoki, et al., "ASCOT: Solving the kinetic equation of minority particle species in tokamak plasmas," Computer Physics Communications, vol.185, pp. 1310-1321, 2014

[24] S. Äkäslompolo et al., "Predictive modelling of NBI ion wall loads in the W7-X stellarator,” Nucl. Fusion, vol. 58, 082010, 2018

[25] S. Äkäslompolo, S. et al, "Armoring of the Wendelstein 7-X divertorobservation immersion-tubes based on NBI fast-ion simulations," Fusion Engineering and Design, in press.

doi: 10.1016/j.fusengdes.2019.01.099

[26] V. Bykov et al., "Engineering Challenges of Wendelstein 7-X Mechanical Monitoring during Second Phase of Operation," Fusion Science and Technology, pp. 7943-7641, 2019.

[27] S. Äkäslompolo, S. et al, "Validating the ASCOT modelling of NBI fast ions inWendelstein 7-X stellarator", submitted to JINST (Journal of Instrumentation, IOP) (papers of 3rd European Conf. on Plasma Diagn., 6.9.May 2019, Lisbon Portugal)

[28] S. Bozhenkov et al., "Measurement and correction of the $1 / 1$ error field for W7-X island", Nucl, Fusion, vol., 59, no.2, p. 26004, 2019. doi: 10.1088/1741-4326/aaf20c

[29] S.Lazerson et al., "Analysis of Wendelstein 7-X divertor load symmetrization", to be submitted to Plasma Physics Contr. Fusion, 2019.

[30] S. Lazerson et al., "Error fields in Wendelstein 7-X stellarator," Plasma Physics Contr. Fusion, vol. 60, no. 12, p. 124002, 2018.

doi: 10.1088/1361-6587/aae9

[31 A Loartes et al., "Plasma detachments if JET Mark I Detachments experiments," Nuclear Fusion, vol. 28. p. 331-371 2018

[32] M. Hirsch a tal., "Major results from the stellarator Wendeslstein 7-AS," Plasma Phys. Contr. Fusion, vol. 50, p. 053001, 2008.

[33] M. Jakubowski et al., "Towards steady-state operation of oisland divertor at Wendelstein 7-X," to be presented at the $22^{\text {nd }}$ Int. Stellarator and Heliotron Workshop", Wisconsing, Septermber20 2019.

[34] G. Ehrke et al., "Design and manufacturing of the Wendelstein 7-X cryovacuum pump," submitted to Fus. Eng. Design, 2019.

[35] ] M. Nagel et al., "Concept for the cryo distribution for the Wendelstein 7-X cryo vacuum pumps,” 2019 IOP Conf. Ser.: Mater. Sci. Eng. 502012109.

doi:/10.1088/1757-899X/502/1/012109

[36] T. Rummel et al. "Upgrade of the cryogenic systems of Wendelstein 7X," to be published in IEEE Trans Plasma Sciences 2019.

[37] J. Onqena et al., "reparing the ICRH system for the Wendelstein 7-X Stellarator,", Preprint 2018: IAEA Fusion Energy Conference, Gandhinagar [EX/P8-27]

[38] A. Winter et al., "Strategy for diagnostics integration into W7-X CoDaC for OP2," to be published in IEEE Trans Plasma Sciences 2019

[39] M. Jacubowski et al, "Infrared Imaging Systems for wall protection in the W7-X stellarator," Rev. Scientific Instruments, vol. 89, no. 10, p. 10E116, 2018 doi: $10.1063 / 1.5038634$

[40] J. Schacht et al., ,Realization of the requirements for a safe operation of Wendelstein 7-X," submitted to Fus. Eng. Design, 2019. 


\section{CVs}

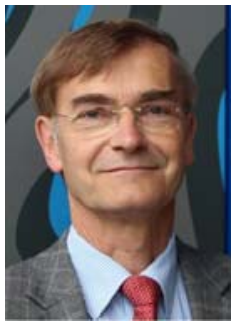

Hans-Stephan Bosch has studied physics in Münster and Munich. He received the Dr. rer. nat. degree from the Technical University, Munich, in 1986, and the Habilitation degree from Humboldt University, Berlin, Germany, in 2000. In August 2016 he was appointed as a professor at TU Berlin.

After his post-doc- time at TFTR in Princeton, he worked on ASDEX and ASDEX Upgrade at IPP, Garching. In 2000 he changed the field, becoming head of the Director's Office. In 2004 he joined the project Wendelstein 7-X as head of Project Coordination. Since 2013 he is the "Director Operations" for Wendelstein 7-X and deputy head of W7-X.

Simppa Äkäslompolo no CV and photo available at the time

Rudolf Brakel no CV and photo available at the time

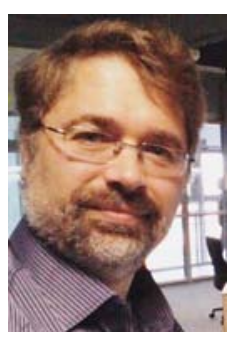

Victor Bykov received the M.Sc. degree in mechanics and control processes from St. Petersburg Polytechnic University, Russia, in 1993, and the Ph.D. degree from the Efremov Institute, Saint Petersburg, in 2013.

He was seconded to the ITER Central Team, Japan, as a Responsible Officer for ITER thermal shield system from 1999 to 2004, after five years with the Efremov Institute. He joined the W7-X project as a Head of the Design and Engineering Department in 2004. He was moved to Operation Sub-Division to lead the Engineering Group, Torus-Hall Department, in 2015.

Peter Drewelow no CV and photo available at the time

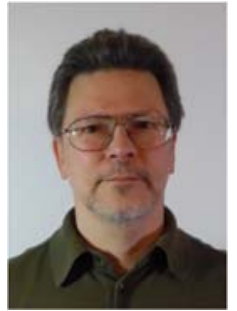

Joachim Geiger received a diploma in physics 1988 at the University of Ulm, Germany, an MS at University of Syracuse, NY, USA, in 1985 and his PhD at the Technical University Munich, Germany in 1992. He joined the IPP in 1992 and has been working in the field of stellarator physics since then at W7-AS in Garching. Since 2001 he joined the Greifswald branch of IPP. He is working in the field of MHD-equilibrium and stability, equilibrium reconstruction and the exploration of the space of magnetic configurations of W7-X.

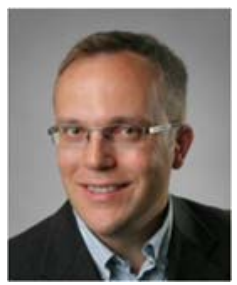

Marcin Jabubowsky received a diploma in physics 1999 at the University of Opole, Poland and his PhD at the Ruhr University Bochum, Germany in 2004. After his Post-Doc at FZJ Jülich, Germany and GA, Samn Diego, USA he joined IPP Greifswald in 2007 and has been working in the field of divertor physics and thermography. He has been appointed a visiting associated professor at NIFS, Japan, University of Szczecin, Poland and University of Cagliari, Italy. Since 2018 he is a group leader of the Imaging and Power Exhaust Group at Wendelstein 7-X.

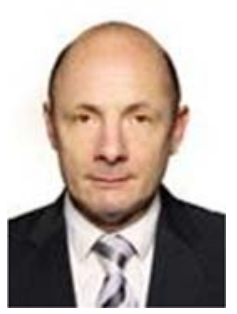

Michael Nagel received the Dipl.-Ing. and Dr.-Ing degrees in Chemical Engineering from the Technical University 1990 and of Karlsruhe (TH), Karlsruhe, Germany, in 1995, respectively.

He joined the Max-Planck-Institute for Plasma Physics, Greifswald, Germany in 1999. He has been involved in cryogenics for Wendelstein 7-X Project. He is leader of the cryogenic team. His working field covers thermodynamics, fluid dynamics and their applications in cryogenics.

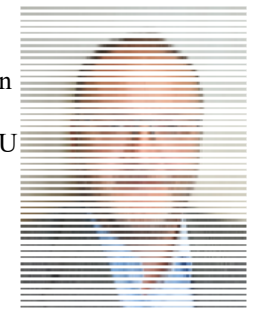

Konrad Risse has studied electrotechnical engineering in Dresden. He received the Dipl.-Ing. degree from the University of Transportation in 1992 He worked as project manager at Siemens and joined the Max-Planck-Institute for Plasma Physics,

Greifswald, Germany in 2000. He work as responsible officer for the superconducting coils of W7-X and for the trim coils respectively. In the W7-X operation phases, he worked as the team leader of the magnet group.

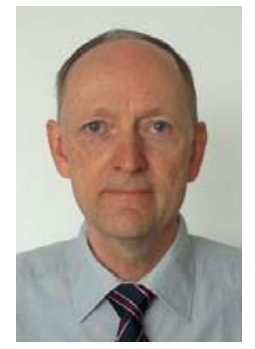

Thomas Rummel has studied Electrical Engineering and received the Dipl.-Ing. and Dr.-Ing. degrees from the university of Magdeburg, Germany, in 1989 and 1996, respectively. He joined the Max-Planck-Institute for Plasma Physics (IPP) Garching in 1998 and has been working for W7-X in the IPP Greifswald in the fields of superconducting magnets, magnet protection and magnet power supplies since then. Since $2015 \mathrm{he}$ is the head of the magnet and cryogenics division of W7-X, which enlarged the working field to the management of cryogenic projects.

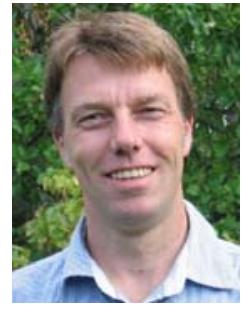

Paul van Eeten received the B.Sc. Degree in aeronautical engineering from the University of Applied Sciences in Haarlem, the Netherlands in 1996.

He worked within the Aero-Engine Industry as a Test Engineer in Munich, Germany, and as an Engineering Representative in Toronto, Canada. In 2005, he received the M.Sc. degree in mechanical engineering from the Royal Institute of Technology, Stockholm, Sweden, after which he joined the W7-X Project as a Structural Engineer performing structural analysis W7-X. He currently works in the Operations Department, planning and conducting the technical operation of W7-X, where he is also involved in change and configuration management within the project. 